\title{
Por que sistematizar a nomenclatura dos defeitos congênitos do coração?
}

\author{
Vera Demarchi Aiello
}

São Paulo, SP

Descrever com acurácia os defeitos congênitos do sistema cardiovascular sempre foi um grande desafio. Inicialmente restrito ao âmbito daqueles que cuidavam de crianças cardiopatas, esse desafio atinge agora o cardiologista que trata de adultos, visto que a cada dia se amplia o número de pacientes que, tratados cirurgicamente na infância, atingem a idade adulta com ou sem seqüelas da sua doença de base ${ }^{1-3}$.

Os primeiros relatos de malformações cardíacas surgiram, esporadicamente, nos séculos XVIII X XIX, mas foi no século XX que foram impressos os dois primeiros importantes compêndios sobre o assunto: os livros da canadense Maude E. Abbott, The Atlas of Congenital Cardiac Disease (1936 - edição completa, com cerca de 1.000 casos descritos) e da americana Hellen B. Taussig, Congenital Malformations of the Heart (1947).

Ainda durante o século XX, evidenciou-se uma nova tendência, e grande parte dos diagnósticos morfológicos baseava-se em conhecimentos de embriologia cardíaca comparada, o que tornava a "arte" de denominar defeitos cardíacos apenas acessível a um seleto grupo de indivíduos ${ }^{4-6}$.

Um problema adicional da nomenclatura é a ocorrência de associação de anomalias, que possibilita inúmeras combinações. Muitos epônimos foram incorporados à prática diagnóstica e alguns persistem em uso até os dias de hoje. "Tetralogia de Fallot", "Síndrome de Shone" e "Anomalia de Taussig-Bing" são exemplos. Outros foram praticamente esquecidos, como por exemplo a "Síndrome de Ivemark" para isomerismos atriais.

Mas foi o início da abordagem operatória das cardiopatias congênitas que tornou essencial a existência de um sistema de nomenclatura que atendesse às expectativas de clínicos, cirurgiões e morfologistas. Além disso, a crescente

Instituto do Coração (InCor) - HC FMUSP

Correspondência: Vera Demarchi Aiello - InCor - Laboratório de Anatomia Patológica - Av. Dr. Enéas C. Aguiar, 44 - 05403-000 - São Paulo, SP

E-mail: anpvera@incor.usp.br

Recebido para publicação em 6/9/01

Aceito em 4/10/01 complexidade das técnicas corretivas exigia uma descrição cada vez mais acurada dos detalhes morfológicos dos defeitos. Com o desenvolvimento dos métodos de diagnóstico morfológico das anomalias, particularmente da ecocardiografia bidimensional, que permite uma abordagem não invasiva dos pacientes, essa descrição tornou-se de importância crucial para a definição de conduta.

Dentro de uma mesma instituição de assistência ou ensino, não é freqüente que exista amplo consenso sobre a denominação de cada defeito. Todavia, alguns hábitos de nomenclatura adquiridos ao longo do tempo têm permitido entendimento entre as diferentes equipes que cuidam desses pacientes, facilitando portanto a troca de informações. No entanto, se o sistema vigente diferir muito do utilizado em outros centros será difícil estabelecer comunicação a fim discutir, por exemplo, diagnóstico, conduta terapêutica e resultados operatórios.

Principalmente, em relação à comparação de resultados operatórios, sociedades médicas internacionais têm recentemente desenvolvido mecanismos de comparação de centros devotados ao tratamento de anomalias cardíacas congênitas, visando apontar as "instituições de baixo risco" para portadores dessa ou daquela anomalia ${ }^{7}$. Esse processo tem obviamente conotação econômica, uma vez que nas referidas instituições o tratamento seria mais eficaz. Para enfatizar a importância da normatização da nomenclatura, permito-me transcrever uma frase que ouvi de um cirurgião cardíaco durante um simpósio. Discutia-se sobre resultados da correção cirúrgica da dupla via de saída do ventrículo direito. Um cirurgião então interpelou o outro com a seguinte pergunta:

- "Mas o que você considera 'dupla via' de saída ventricular? Se você quiser melhorar os seus resultados de dupla via, é só incluir na casuística aqueles pacientes com tetralogia de Fallot e grande acavalgamento da aorta sobre o ventrículo direito...".

Da mesma forma, outras anomalias mostram particularidades de apresentação que podem modificar o prognóstico e que, portanto, merecem descrição cuidadosa.

Duas perguntas afligem particularmente os envolvi- 
dos no diagnóstico e no tratamento das anomalias congênitas do coração: 1) qual seria o sistema mais adequado e eficiente de classificação?; 2) será possível atingir um consenso sobre nomenclatura?

Haverá muitas opiniões divergentes relativas à primeira pergunta, principalmente por que existem tendências regionais muito fortes. Além disso, a simples observação mostra que instituições de assistência e ensino estabelecidas há bastante tempo tendem a manter em linhas gerais o sistema adotado desde o início, enquanto que aquelas surgidas mais recentemente costumam considerar novas propostas, desde que essas atendam a mínimos requisitos.

A análise individualizada e seqüencial dos segmentos cardíacos proposta inicialmente por Van Praagh ${ }^{8}$ constituiu-se em grande avanço, pois começava a sistematizar a observação dos defeitos cardíacos. Todavia, essa abordagem leva em conta o arranjo e relação espacial externos dos segmentos cardíacos e grandes artérias e não a conexão interna das câmaras e vasos entre si. Por outro lado, analisar o "como" se conectam essas estruturas ao mesmo tempo descreve a anatomia e faz inferir a fisiologia da anomalia. Essa contribuição (descrição sistematizada da conexão interna entre câmaras e vasos) foi fornecida pelo grupo europeu $^{9,10}$, sendo rapidamente aceita e progressivamente disseminada em diversos centros emergentes de cardiologia.

A despeito da aprovação desse sistema descritivo, controvérsias apareceram no que se refere ao "descrever" versus "denominar" anomalias. Embora o "denominar" possa ser mais conciso, o "descrever" é sem dúvida mais preciso. A opção sem dúvida fica com cada grupo ou instituição. É claro também que existem determinados epônimos e denominações consagrados amplamente pelo uso contínuo, os quais não devem ser abandonados, pois já provaram ser nomes eficientes.

Particularmente, na minha experiência e rotina diária tornou-se mais simples o sistema descritivo. Devo porém confessar que posso representar um viés no grupo de profissionais que utilizam nomenclatura de defeitos congênitos, pois comecei a me interessar pelo problema quando o sistema europeu de análise segmentar seqüencial estava em pleno desenvolvimento, nos anos 80 . Tive a oportunidade de conviver com colegas que viveram a fase anterior e testemunhei sua adesão (não sem antes travar acaloradas discussões) ao novo sistema, em virtude das grandes vantagens que ele oferecia. A maior delas foi sem dúvida a desmistificação da terminologia, uma vez que, com conhecimentos básicos de anatomia que permitam a correta identificação de câmaras e estruturas, mesmo um novato poderá acuradamente descrever um defeito.

Entretanto, a utilização contínua do referido sistema mostrou alguns "pontos fracos", como por exemplo: avaliar a porcentagem de acavalgamento de um orifício valvar sobre o septo é, por vezes, tarefa difícil, principalmente nos casos limítrofes, mas poderá mudar completamente a definição do tipo de conexão (atrioventricular ou ventrículo-arterial); a descrição da conexão entre átrios e ventrículos baseia-se nesse último segmento (ventricular) e é definida como univentricular ou biventricular. Existem todavia raras ocasiões onde a conexão é biventricular e uniatrial (aqueles raros casos onde um dos átrios tem assoalho muscular completo - ausência de conexão - e a única valva atrioventricular presente acavalga o septo ventricular, conectando-se também com o ventrículo rudimentar). Da forma como foi concebido, o sistema de nomenclatura não contempla as anomalias citadas acima. Mas sempre será possível descrevê-las, ressaltando que fazem parte de um grupo particular e extremamente raro.

Acredito que as vantagens, apresentadas pelo sistema, superam amplamente os inconvenientes mencionados. Além disso, nos dias de hoje, a disputa travada em torno dos termos "ventrículo único e coração univentricular", certamente, já se dissipou, com o entendimento claro de que nesses casos o que é univentricular é a conexão atrioventricular e não o coração em si ${ }^{11}$. Se deixarmos de lado ainda o caráter passional da questão, será também legítimo aceitar o termo ventrículo único como descritivo da fisiologia do defeito.

A resposta à segunda pergunta leva-nos à reflexão sobre a necessidade de comunicação. Qualquer que seja o sistema adotado, comunicar-se é imperioso e esforços estão se concentrando na tentativa de, se não atingirmos consenso, pelo menos conseguirmos trocar idéias. Dois importantes grupos já publicaram suas experiências iniciais sobre o assunto: trata-se da Sociedade de Cirurgiões Torácicos (STS) e da Sociedade Européia de Cardiologia Pediátrica. Embora tenham surgido separadamente, essas iniciativas foram praticamente concomitantes e demonstram a urgência que o tema exige. Os sistemas de nomenclatura apresentados nessas duas publicações apresentam diferenças na estrutura geral, porém uma comissão mista representativa das duas associações já trabalha no sentido de mapear os códigos de ambos para que as comparações sejam possíveis.

Com sólida tradição na abordagem e tratamento das cardiopatias congênitas, o nosso país não deve ser omisso nessa questão. Tanto os menores serviços de Cardiologia até os centros mais consolidados beneficiar-se-ão de uma discussão de âmbito nacional, que permita a adoção de um sistema que atenda às nossas particularidades e preferências, evitando a aceitação pura e simples dos sistemas já publicados.

\section{Agradecimento}

Ao Prof. Luiz V. Décourt, pelas valiosas sugestões e informações históricas. 


\section{Referências}

1. Somerville J. Management of adults with congenital heart disease: an increasing problem. Ann Rev Med 1997; 48: 283-93.

2. Perloff JK, Lindgren KM. Adult survival in congenital heart disease: uncommon defects with expected adult survival. Geriatrics 1974; 29: 99-109.

3. Oechslin EN, Harrison DA, Connely MS, Webb GD, Siu SC. Mode of death in adults with congenital heart disease. Am J Cardiol 2000; 86: 1111-6.

4. Goor DA, Edwards JE. The conotruncus. II. Report of a case showing persistent aortic conus and lack of inversion of the truncus (a bulboventricular heart). Circulation 1972; 46: 385-9.

5. Van Praagh R, Van Praagh S, Vlad P, Keith JD. Anatomic types of congenital dextrocardia: diagnostic and embryologic implications. Am J Cardiol 1964; 13: 510-31.

6. Medeiros Sobrinho JH, D'Oliveira LG, Falci M, Santos RG, Lima AB. Defeitos do septo auricular. I- Embriologia e tipos anatômicos. Arq Bras Cardiol 1960; 13: $181-211$.
7. Kirklin JW, Blackstone EH, Tchervenkov CI, Castaneda AR. Clinical outcomes after the arterial switch operation for transposition: patient, support, procedural, and institutional risk factors. Congenital Heart Surgeons Society. Circulation 1992: 86: 1501-15.

8. Van Praagh R. Terminology of congenital heart disease: glossary and commentary. Circulation 1977; 56: 139-43.

9. Tynan MJ, Becker AE, Macartney FJ, Quero-Jimenez M, Shinebourne EA, Anderson RH. Nomenclature and classification of congenital heart disease. $\mathrm{Br}$ Heart J 1979; 41: 544-53.

10. Anderson RH, Ho SY. Sequential segmental analysis- description and categorization for the millenium. Cardiol Young 1977; 7: 98-116.

11. Anderson RH, Becker AE, Tynan M, Macartney FJ, Rigby ML, Wilkinson JL. The univentricular atrioventricular connection: getting to the root of a torny problem. Am J Cardiol 1984; 54: 822-8.

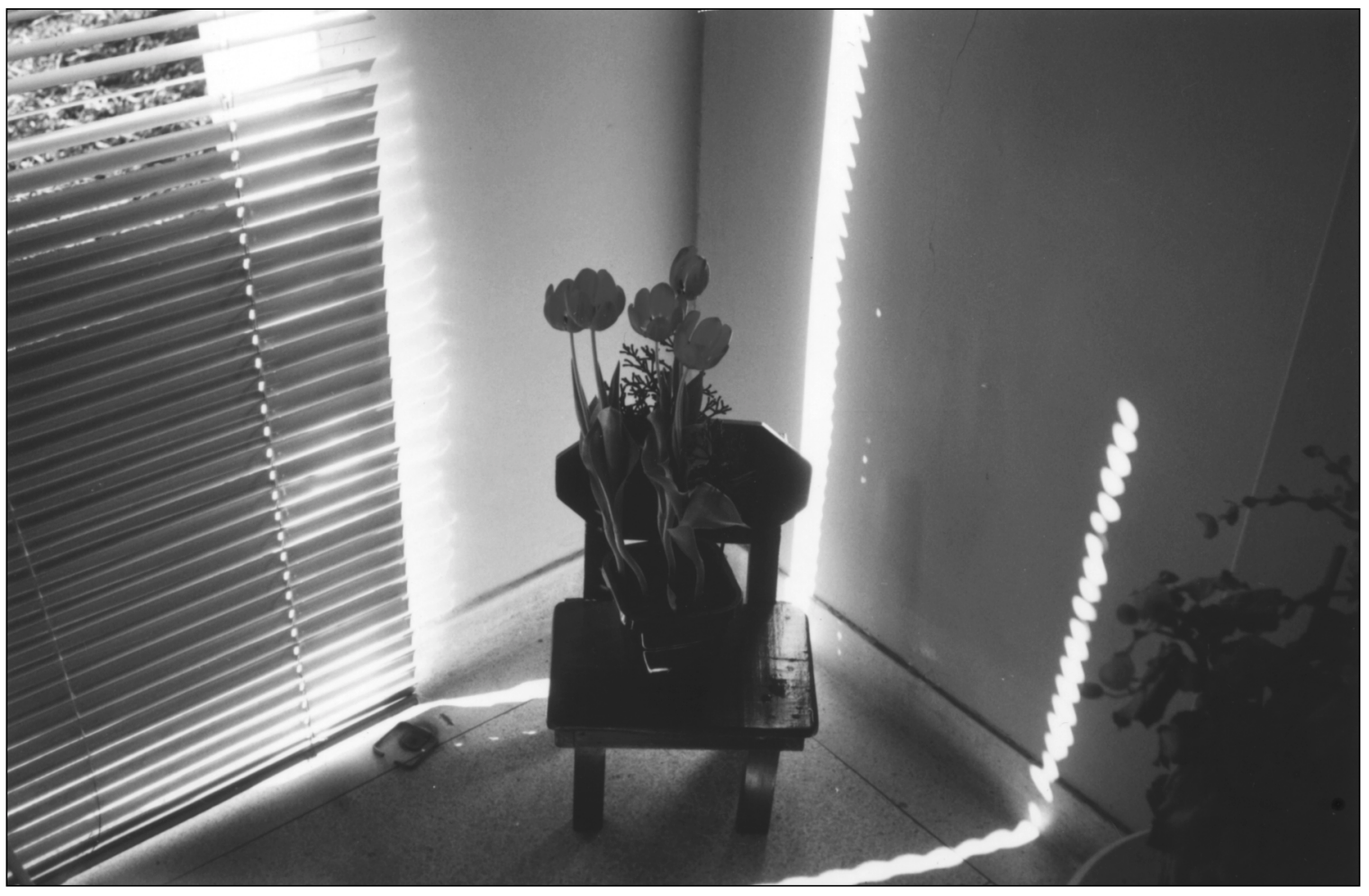

Tulipas oferecidas para a Vó, pelo Dr. Armando

Maria Cecília B. C. Decaurt Vita

Editor da Seção de Fotografias Artísticas: Cícero Piva de Albuquerque

Correspondência: InCor - Av. Dr. Enéas C. Aguiar, 44 - 05403-000 - São Paulo, SP - E-mail: delcicero@incor. usp.br 